\title{
Metodologias Ativas de Aprendizagem: Estudo sobre a Problematização da Realidade Social na Disciplina de Psicologia, Educação e Temas Contemporâneos na EACH-USP
}

\author{
Patrícia Junqueira Grandino \\ Escola de Artes, Ciências e Humanidades da Universidade de São Paulo \\ * Autora para correspondência: patjg@usp.br
}

\begin{abstract}
RESUMO
Apresentamos aqui o relato de experiência de docência sustentada em metodologia de PBL, desenvolvida na Escola de Artes, Ciências e Humanidades da USP. Na disciplina de Psicologia, Educação e Temas Contemporâneos, assumimos o compromisso de questionar a realidade contemporânea a partir de pressupostos da psicologia e da educação, tecendo um quadro teórico crítico que desloca o debate do senso comum em direção a uma reflexão crítica e elaborada das questões emergentes da realidade social. Grupos de alunos elegem uma temática atual e desenvolvem uma investigação considerando as referências teóricas da disciplina, uma contextualização crítica da temática eleita e a realização de uma entrevista com ferramentas para desenvolver empatia (em parceria com o d-USPLeste: Laboratório de Design, Inovação e Criatividade). Os resultados apontam para uma maior qualidade na reflexão crítica, valorização da diversidade humana, quebra de estereotipias, maior facilidade de relacionamento entre estudantes e um ganho significativo na abrangência de temas sociais com enfoque interdisciplinar.
\end{abstract}

Palavras-chave: Formação; Graduação; PBL; Design Thinking.

\begin{abstract}
We present the report on teaching experiences sustained in the PBL methodology, developed at the Escola de Artes, Ciências e Humanidades of the Universidade de São Paulo. In the psychology discipline, Education and Contemporary Themes, we committed ourselves to question the contemporary reality, based on psychological and educational assumptions, weaving a critical theoretical overview that shifts the debates from the commonplace to an elaborate, critical reflection over rising issues of social reality. Groups of students elected a modern theme and develop an investigation, considering theoretical references from the discipline, critical contextualization of the chosen theme and finally the development of interviews with tools to generate empathy (through a partnership with d-USPLeste: Laboratório de Design, Inovação e Criatividade). Results point to greater quality on critical reflection and the appreciation of human diversity, as well as a break with stereotypes, facilitating relationship between students and a significative gain on the range of social themes with a multidisciplinary focus.
\end{abstract}

Keywords: Formation; Undergraduate Degree; PBL; Design Thinking.

\section{Projeto Pedagógico e Articulação de Disciplinas}

Este trabalho relata a experiência de docência sustentada na metodologia de Aprendizagem Baseada em Problemas $(\mathrm{ABP})^{1}$. Buscando inverter a didática tradicional focada na transmissão do conhecimento, ainda fortemente presente nos cursos de formação universitária, assumimos as metodologias ativas de aprendizagem como foco central de construção do conhecimento.
Colocado no centro do processo de aprendizado, o estudante passa a ser convocado a implicar-se nos conteúdos abordados pela disciplina, de modo a reconhecer sua pertinência e a tecer significados próprios que darão maior densidade aos temas trabalhados em sala.

Desenvolvida na Escola de Artes, Ciências e Humanidades da Universidade de São Paulo (EACH-USP), essa experiência insere-se no projeto pedagógico da unidade e corresponde aos seus 
objetivos de formação diferenciada e inovadora. Trata-se de uma unidade de Ensino Superior recente dentro da Universidade de São Paulo - cujo primeiro ano letivo ocorreu em 2005 - e que tem como compromisso oferecer formação humanista, crítica e abrangente, por meio de estruturas curriculares que permitem a interlocução entre diferentes campos do conhecimento e áreas de atuação. Desde seu projeto de implantação, tem como pressupostos fundamentais a interdisciplinaridade e a preocupação em garantir espaços de inovação pedagógica, valorizando metodologias de ensino e aprendizagem que promovam em nossos estudantes a autonomia, o reconhecimento da complexidade do pensamento e uma postura propositiva diante dos desafios atuais.

Para tanto, conta com um primeiro ano letivo geral a todos os dez cursos de graduação, o qual oferece anualmente - com carreiras interdisciplinares envolvendo as áreas de humanidades, ciências naturais e exatas ${ }^{2}$, cujo objetivo é o de apresentar aos estudantes ingressantes na universidade a complexa heterogeneidade do pensamento científico e a diversidade epistemológica dos campos de conhecimento, convocando-os a compreender as questões da realidade social mais ampla em profundidade.

Este ano inicial, chamado de Ciclo Básico ${ }^{3}$, tem como eixo articulador a disciplina de Resolução de Problemas que, por meio da metodologia da Aprendizagem Baseada em Problemas (ABP), trabalha com turmas compostas por alunos de diferentes cursos. Subdivididos em pequenos grupos - e acompanhados por um docente tutor -, tomam por encargo a problematização de um tema geral. Em cada um dos dois primeiros semestres letivos, os subgrupos devem debruçar-se sobre um problema construído pelo grupo e buscar abordá-lo teórica e metodologicamente com os procedimentos previstos pela investigação científica. Ao final do semestre, apresentam e compartilham com o restante da turma o relatório final e os resultados da investigação realizada.

Além dessa disciplina, a grade do Ciclo Básico compreende duas disciplinas introdutórias, es- pecíficas ao curso, e três disciplinas gerais a cada semestre. Estas últimas têm por objetivo central introduzir o aluno ingressante num conjunto ampliado de áreas e campos de conhecimento, de modo a compor um quadro inicial de reflexão crítica a respeito das contribuições científicas e qualificar a discussão sobre cidadania, direitos humanos e questões ambientais.

Cabe salientar que um dos maiores desafios dessa proposta pedagógica está em construir no cotidiano da unidade a interdisciplinaridade prevista no projeto, considerando a diversidade teórica dos docentes, seus campos de investigação e a formação tradicional da qual também somos herdeiros. Outro forte desafio está no trabalho necessário sobre a expectativa dos alunos com relação aos temas que lhes serão apresentados nas disciplinas gerais. Assim como em Resolução de Problemas, também as turmas das disciplinas gerais são compostas com alunos de diferentes cursos. Se, por um lado, a diversidade de interesses e expectativas que eles demonstram gera ambiente propício para a convivência universitária mais flexível e heterogênea, por outro também permite trabalhar conflitos que de outro modo emergiriam de forma velada, ou provocariam a distância e sectarismo dos grupos. Mas, do ponto de vista da construção da proposta curricular de cada uma dessas disciplinas, apresenta-se o desafio de encontrar um eixo que garanta a contribuição formativa para cursos tão diferentes entre si e, ao mesmo tempo, que se desperte o interesse no aluno ingressante, mesmo com temáticas bastante distintas do campo de conhecimento de seu curso, como pode ser o caso, por exemplo, de abordar temas de Psicologia e Educação com estudantes do curso de Sistemas de Informação ou Marketing.

\section{A Contemporaneidade sob o Olhar da Psi- cologia e da Educação}

Na disciplina geral de Psicologia, Educação e Temas Contemporâneos, temos desenvolvido uma proposta pedagógica que consiste em questionar a realidade contemporânea a partir de pressupostos da Psicologia e da Educação. Nosso objetivo é 
tecer um quadro teórico crítico de referência que desloque o debate do senso comum em direção a uma reflexão mais adensada, crítica e elaborada das questões emergentes da realidade social.

Partimos de uma caracterização crítica desse tempo histórico, com base em contribuições de Birman (2006) e Bauman (2011) e apontamos algumas singularidades da dinâmica atual, destacando os paradoxos que marcam a experiência humana na atualidade. Dado esse marco inicial, tomamos como eixo de reflexão duas questões centrais: a) a produção de subjetividade no mundo contemporâneo e suas consequências para os sujeitos; e b) o papel do conhecimento nas sociedades contemporâneas. Essas duas unidades temáticas formam o pano de fundo teórico que se desenrolará durante o semestre, e sustentam-se em contribuições teóricas de autores da psicologia, psicanálise e educação ${ }^{4}$. Sobre essas duas unidades cada grupo de estudantes deverá eleger uma questão social contemporânea e construir um quadro analítico crítico. O objetivo explicitado aos alunos é que sejam capazes de abandonar gradualmente a perspectiva de senso comum com que a sociedade aborda esse tipo de temática e, do ponto de vista de cidadãos universitários e formadores de opinião, possam construir uma argumentação consistente e desprovida de estereótipos.

Desde o ano de 2011 adotamos, como atividade complementar, a estratégia de realização de entrevistas sob o modelo com que trabalha o Design Thinking, do d-USPLeste: Laboratório de Design, Inovação e Criatividade da EACH-USP, implantado no mesmo ano na EACH-USP. Essa ferramenta é fundamental na disciplina para o processo de construção de empatia e para o desenvolvimento de novos projetos que atendam as demandas de grupos sociais. Espera-se que o entrevistador seja capaz de reconhecer a questão abordada do ponto de vista do entrevistado, identificando suas crenças, representações e sentido atribuído àquilo que se procura abordar. $\mathrm{O}$ recurso foi trabalhado em aula e vivenciado pelos estudantes que, à guisa de exercício, colocaram-se alternadamente nos papéis de entrevistado e entrevistador. Nesta ocasião, e ao longo do semestre, as questões éticas que envolvem a investigação acadêmica com seres humanos foram fortemente reiteradas.

Com esse recurso, os estudantes tiveram a oportunidade de abordar questões atuais e muitas vezes polêmicas, presentes no debate social e, com a aproximação cuidadosa e estruturada promovida pela disciplina, ampliar sua sensibilidade para os temas que afetam a realidade social atual e reduzir posturas estereotipadas em relação a elas.

A autonomia dos alunos para decidirem o foco do trabalho dentre um leque de questões atuais (violências, drogas, sexualidade, entre outros) permitiu que, no conjunto, se observasse um mosaico bastante diversificado de interesses e questionamentos. A diversidade de temas pode ser reconhecida pelos exemplos abaixo indicados:

- Compulsão por jogos de azar - este grupo investigou, entre diferentes tipos de comportamento aditivo, as características dessa modalidade de adição e as consequências para os envolvidos;

- Corporeidade e prostituição masculina - o grupo abordou o tema do culto ao corpo entre homens que se prostituem;

- Coletivo de mulheres contra a violência - o foco da investigação do grupo foi a organização política de um grupo que atua na luta contra a violência doméstica;

- Esportes de risco - interessante abordagem a grupos de jovens que praticam "rachas" e parkour em São Paulo;

O trabalho dos grupos consistiu, inicialmente, em abordar o tema selecionado buscando fontes de referências acadêmicas sobre a questão. Após a caracterização da problemática, os estudantes tiveram que estabelecer relações com os textos de referência da disciplina, autores do campo da Psicologia, Psicanálise e Educação, de modo a reconhecerem, com essas contribuições, a interlocução possível entre realidade prática e debate acadêmico.

$\mathrm{O}$ teor polêmico de muitos temas possibilitou trabalhar pedagogicamente em aula a formação dos preconceitos sociais. Como critério para o debate e o enfrentamento das questões, adotamos uma perspectiva investigativa despida de 
conotações moralizadoras e ajuizadoras, a fim de favorecer a compreensão analítica e o distanciamento do debate de senso comum.

A terceira etapa do trabalho consistiu na realização de uma entrevista com algum sujeito ligado à questão foco de cada grupo, com a ferramenta do Design Thinking para o desenvolvimento de empatia. Os grupos, então, fizeram uma entrevista com profissionais, ou pessoas envolvidas diretamente nas temáticas abordadas.

Ao final do semestre os grupos procederam a uma socialização dos resultados de seus trabalhos, compartilhando o impacto da atividade em sua formação. Foram convidados a expressarem suas reflexões de maneira criativa e buscando sensibilizar outras pessoas para as considerações que alcançaram com o término do trabalho.

\section{Comentários Complementares}

$\mathrm{Na}$ atualidade, a formação universitária exige que se compreendam e exercitem modalidades pedagógicas que façam frente ao dinamismo e às exigências expressas no mundo e que sejam distintas da mera instrumentalização das novas gerações, que compromete a formação crítica, geradora de autonomia e de transformação social.

Trazer o estudante para o centro da experiência educativa significa romper com a postura passiva em relação ao conhecimento e permite que a relação ensino-aprendizagem se estabeleça de maneira horizontalizada e simétrica, sem que isso acarrete a descaracterização dos papéis de docentes e estudantes. A relação com o conhecimento passa a ser mediatizada pela realidade social, e a análise crítica encontra nos pressupostos teóricos os elementos constitutivos de um quadro interpretativo que fundamenta a ciência, em suas várias áreas, de forma viva, atual e implicada com a realidade.

Dessa maneira, na experiência da disciplina de Psicologia, Educação e Temas Contemporâneos, pudemos observar, ao longo do semestre, um gradual avanço na qualidade da elaboração discursiva dos estudantes, caracterizada por questionamentos apresentados em aula com maior potencial de criticidade e maior capacidade de análise; maior valorização da diversidade humana, em razão da quebra de estereotipias; maior entrosamento e facilidade relacional entre estudantes de diferentes cursos e um ganho significativo na abrangência de temas sociais com enfoque interdisciplinar.

\section{Notas}

$1 \mathrm{Ou}$ PBL - Problem-based Learning, em inglês.

2 Os cursos de graduação da EACH-USP são: Gestão de Políticas Públicas, Gestão Ambiental, Lazer e Turismo, Têxtil e Moda, Sistemas de Informação, Licenciatura em Ciências da Natureza, Marketing, Gerontologia, Obstetrícia, Educação Física e Saúde. Para maiores detalhes e informações, ver: $<$ www.each.usp.br>.

3 Em 2012, houve uma reformulação do ciclo básico, que buscou adequar-se à organização curricular específica dos cursos de graduação, estabelecendo, a critério de cada comissão de curso, a manutenção da sua oferta nos dois primeiros semestres da grade ou ao longo de seis semestres. Entre outras mudanças, houve uma subdivisão das disciplinas gerais, que permanecem obrigatórias. Não se alterou a estrutura geral do Ciclo Básico. Para detalhes, consultar a estrutura curricular dos cursos de Graduação da EACH em: <http://www5.each.usp. br/apresentacao-graduacao/>.

4 Como, por exemplo: Costa (2007), Enriquez (2001), Demo (2000).

5 Parkour é uma atividade de risco que consiste em mover-se com eficiência e rapidez, superando obstáculos com a utilização de manobras feitas com o próprio corpo, usando, para tanto, principalmente as habilidades do corpo humano.

\section{Referências Bibliográficas}

BAUMAN, Zygmunt. Vida em Fragmentos: sobre Ética Pós-Moderna. Rio de Janeiro: Zahar, 2011.

BIRMAN, Joel. Arquivos do Mal-Estar e da Resistência. Rio de Janeiro: Civilização Brasileira, 2006.

COSTA, Jurandir Freire. "O Self e a Interioridade" (capítulo 2). In: O Risco de Cada Um. Rio de Janeiro: Garamond, 2007.

DEMO, Pedro. "Ambivalências da Sociedade da Informação". Ci. Inf. [on-line], vol. 29, n. 2, maio/ago. 2000. Disponível em: http://www.scielo.br/pdf/\%0D/ci/ v29n2/a05v29n2.pdf. Acessado em jun. 2007.

ENRIQUEZ, Eugéne. "A Interioridade Está Acabando?". In: MACHADO, M. N. M.; CASTRO, E. M.; 
ARAÚJO, J. N. G. \& ROEDEL, S. (orgs.). Psicossocio- MELO, Isabela (cols.). "IDEO. HCD: Human Cenlogia: Análise Social e Intervenção. São Paulo: Autêntica, tered Design - Toolkit". Disponível em: https://www. 2001. ideo.com/work/human-centered-design-toolkit/. AcesRIBEIRO, Tennyson; COLUCGI JR., José \& sado em 15 jul. 2013.

Publicado em 30/06/2017. 